\title{
Posterior communicating artery aneurysm associated with duplicated posterior communicating artery and bilateral fetal posterior cerebral arteries
}

Sir,

A 60-year-old man presented to us with sudden severe headache since two days. NCCT revealed subarachnoid hemorrhage and a diagnosis of ruptured aneurysm was entertained. Digital subtraction angiography revealed a posterior communicating artery (PcomA) aneurysm with duplicated PComA and bilateral fetal posterior cerebral arteries (PCAs) [Figure 1]. Microsurgical clipping was performed with preservation of both PcomAs [Figure 2], with an excellent postoperative course.

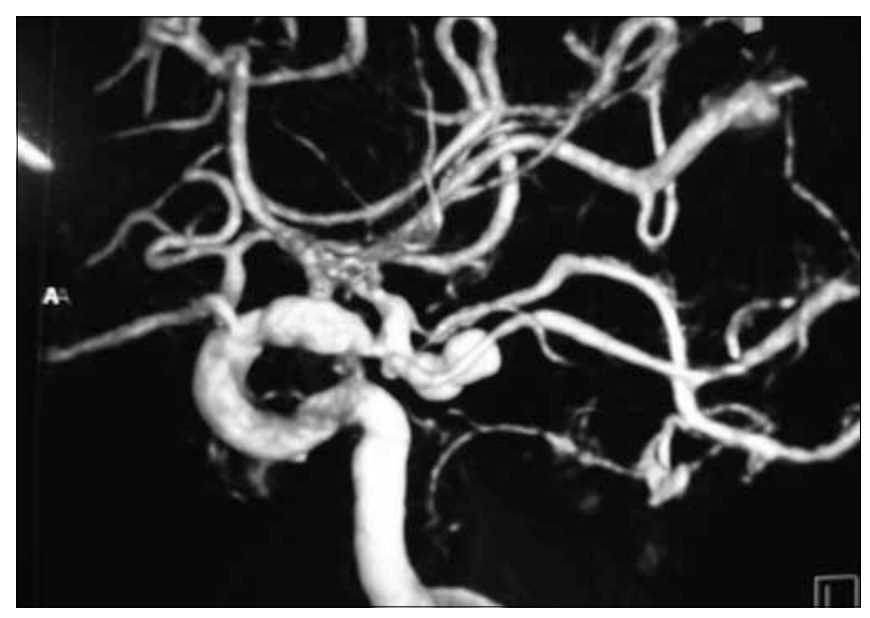

Figure 1: 3D digital subtraction angiography showing a posterior communicating artery aneurysm with presence of bilateral fetal posterior cerebral artery and duplicated posterior communicating artery

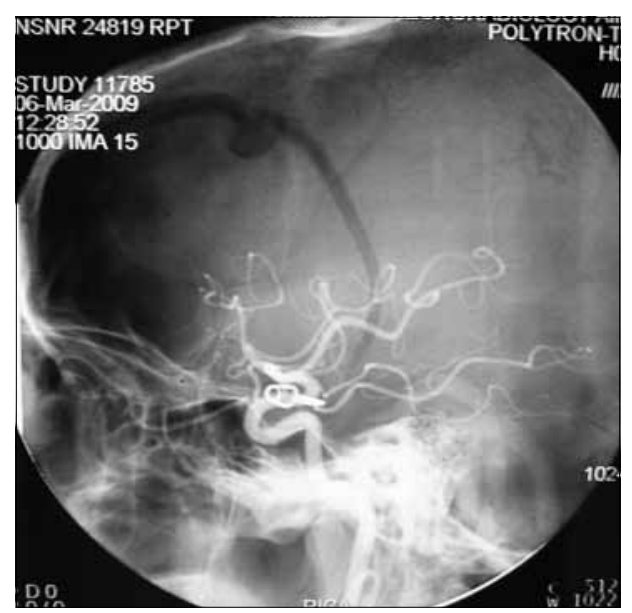

Figure 2: Postoperative angiography showing a well-clipped aneurysm with preservation of both the posterior communicating arteries 
Presence of fetal PCA in association with PcomA aneurysms makes surgery challenging as preservation of PcomA becomes vital to ensure vascular supply in the PCA territory. This is because the PCA territory is being perfused predominantly from the ICA through the PcomA in patients with fetal PCA. Duplication of the PcomA is a rare variation in which two arteries arise independently from the ICA and accounts for less than $0.2 \%$ of anatomical variations in cerebral vasculature. ${ }^{[1]}$ Though anatomical variations like aplasia and fenestration of PcomA have been reported, ${ }^{[2,3]}$ presence of bilateral fetal PCA with a duplicated PcomA in association with a PcomA aneurysm is distinctly rare. ${ }^{[1]}$ Knowledge of such an anatomical variation is surgically important to prevent inadvertent complications.
Noufal Basheer, Manish K. Kasliwal, Ashish Suri

Department of Neurosurgery, All India Institute of Medical Sciences,

New Delhi, India.

E-mail : surineuro@hotmail.com

\section{References}

DOI: $10.4103 / 0028-3886.55592$

1. Hashimoto M, Urasaki E, Tsujigami S, Yokota A. Ruptured aneurysm associated with partially duplicated posterior communicating artery-case report. Neurol Med Chir (Tokyo) 2002;42:23-6.

2. Tripathi M, Goel V, Padma MV, Jain S, Maheshwari MC, Gaikwad S, et al. Fenestration of the posterior communicating artery. Neurol India 2003;51:75-6.

3. Banach MJ, Flamm ES. Supraclinoid internal carotid artery fenestration with an associated aneurysm. Case report. J Neurosurg 1993;79:438-41.

Accepted on 25-03-2009 